\title{
Failure of everolimus in the management of Kaposi's sarcoma in HOPE Act recipient following simultaneous liver and kidney transplantation
}

\author{
Varvara A Kirchner ${ }^{1}$, Timothy L Pruett ${ }^{1}$ and Daniel O Keys ${ }^{2}$ \\ ${ }^{1}$ Division of Transplantation, Department of Surgery, University of Minnesota, Minneapolis, MN, USA \\ ${ }^{2}$ Division of Nephrology and Hypertension, Department of Medicine, University of Minnesota, MN, USA
}

\begin{abstract}
Abbreviations: DNA: deoxyribonucleic acid; HAART: highly active antiretroviral therapy; HHV-8: human gammaherpesvirus 8; HIV: human immunodeficiency virus; HOPE Act: the HIV Organ Policy Equity Act; KS: Kaposi's sarcoma; MMF: mycophenolate mofetil; mTOR inhibitor: the mammalian target of rapamycin inhibitor; RNA: ribonucleic acid; SLKTx: simultaneous liver kidney transplant
\end{abstract}

\section{Dear Editors,}

It is expected that HIV-related immunodeficiency, cirrhosisassociated cytopenia and potent immunosuppression put simultaneous liver and kidney transplant (SLKTx) recipients with HIV at increased risk of infections and malignancies such as Kaposi's sarcoma (KS). Surprisingly, existing data suggest that incidence and severity of KS are similar between HIV+ and HIV- transplant recipients, and require similar management with reduction of the immunosuppression and transition to mTOR inhibitor [1]. The benefit of mTOR inhibition by sirolimus for KS has been demonstrated in transplant and nontransplant populations; however, the data on everolimus in KS patients are limited [2]. A multicenter trial of everolimus in classic KS failed to show the oncologic benefit [3]. In transplant population, the everolimus experience for management of KS has been limited to a few case reports and its anti-tumor properties have not demonstrated a consistent success [4]. We report a case of de novo KS in a HOPE Act SLKTx recipient that was resistant to everolimus, but with transition to sirolimus demonstrated significant tumor reduction.

The recipient is a 46-year-old gentleman with end-stage liver and chronic kidney disease. He was diagnosed with HIV in 1999 and initiated HAART in 2002 without history of antiretroviral resistance. At the time of transplant, his HIV-1 RNA was non-detectable and CD4 count was 129 . The SLK offer from a 37 -year-old brain-dead donor became available. The donor had history of HIV since 2005, was on HAART at the time of the donation with 6,038 copies/ml of HIV-1 RNA and CD4 count of 7 .

The recipient underwent induction with thymoglobulin $(3 \mathrm{mg} /$ $\mathrm{kg}$ ) and methylprednisolone, and was started on tacrolimus and mycophenolate mofetil (MMF). His chemoprophylaxis included sulfamethoxazole/trimethoprim and valganciclovir. Post-operatively his liver function tests have normalized and creatinine stabilized at 2.25 $\mathrm{mg} / \mathrm{dl}$. His early course was complicated by arrhythmias, pneumonia, tracheostomy, malnutrition, presumed mycobacterium avium complex infection and borderline cellular rejection of the kidney managed with pulse steroids.
Four months post-SLKTx, patient developed $2.5 \times 2 \mathrm{~cm}$ purple plaque adjacent to his liver transplant incision (Figure 1A). The punch biopsy was consistent with KS, characterized by dense vascular proliferation of anastomosing vascular channels with plump, spindled endothelial cells, +HHV8 stain and abundant extravasated erythrocytes. At the time of KS diagnosis, his CD4 count was 93.

The management included transition from tacrolimus (level 8ng/ $\mathrm{mL}$ )/MMF to everolimus alone (level $12 \mathrm{ng} / \mathrm{ml}$ ). It was elected not to pursue doxorubicin treatment given patient's preexisting pancytopenia. During the 5-month everolimus monotherapy, the tumor persisted (Figure 1B). HHV-8 was detected at 47 DNA molecules/microliter. Patient was transitioned to sirolimus (level $15 \mathrm{ng} / \mathrm{ml}$ ) monotherapy, with significant tumor reduction two months after the switch (Figure 1C). Simultaneously, his CD4 count increased to 140 and HHV-8 quantitative PCR became non-detectable.

This case emphasizes the complex balance of managing an opportunistic disease in immunocompromised and debilitated HOPE Act SLKTx recipient with low CD4 counts and history of rejection. Minor structural differences, bioavailability, hepatic metabolism and tissue distribution of mTOR inhibitor analogs may have important clinical consequences [5]. Therefore, further investigations are needed to understand if everolimus is efficacious in management of KS in HIV+ recipients.
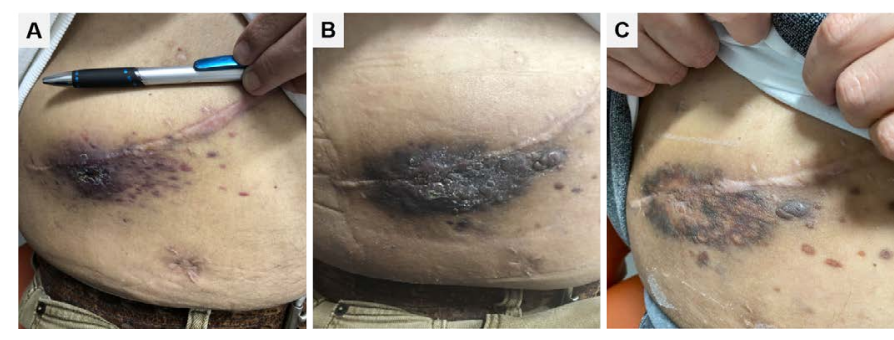

Figure 1. Evolution of the Kaposi's sarcoma lesion over the course of mTOR inhibitor therapy

*Correspondence to: Varvara A. Kirchner, MD, 412 Delaware Street SE, MMC 195, Minneapolis, MN 55408, Tel: 1-612-625-7600; Fax: 1-612-624-7168; E-mail: kirc0079@umn.edu

Key words: Kaposi's sarcoma, sirolimus, everolimus, HOPE Act, transplantation

Received: July 13, 2020; Accepted: July 22, 2020; Published: July 27, 2020 


\section{Authorship}

Varvara A Kircher

1. Participated in research design.

2. Participated in the writing of the paper.

3. Participated in the performance of the research.

Timothy L. Pruett

1. Participated in research design.

2. Participated in the writing of the paper.

3. Participated in the performance of the research. Daniel O. Keys

1. Participated in research design.

2. Participated in the writing of the paper.

3. Participated in the performance of the research.

\section{Disclosure}

"The authors declare no conflicts of interest."

\section{Funding Sources}

"The authors have no funding to disclose."

\section{Acknowledgements}

Authors would like to acknowledge Drs. Winston P. Cavert, JoAnne H. Young, Thomas M. Leventhal and Mr. Jeff Strowbridge.

\section{References}

1. Charpentier C, Delyon J, Glotz D, Peraldi M, Rerolle J, et al. (2019) Kaposi Sarcoma in HIV-positive Solid-Organ Transplant Recipients: A French Multicentric National Study and Literature Review. Transplantation 103: e22-e28. [Crossref]

2. Yaich S, Charfeddine K, Zaghdane S, N El Aoud, F Jarraya, et al. (2012) Sirolimus for the treatment of Kaposi sarcoma after renal transplantation: a series of 10 cases. Transplant Proc 44: 2824-2826. [Crossref]

3. Porcher R, Kerob D, Dupin N (2011) Multicentric phase II clinical trial evaluating the role of everolimus (RAD001) in endemic or classic Kaposi's sarcoma. Journal of Clinical Oncology 29: 10067-10067.

4. Vergoulas G, Miserlis G, Leontsini M, Papanikolaou V, Takoudas D (2008) De novo and recurrent Kaposi's Sarcoma after renal transplantation in two patients taking everolimus. Hippokratia 12: 191-192. [Crossref]

5. MacKeigan JP, Krueger DA (2015) Differentiating the mTOR inhibitors everolimus and sirolimus in the treatment of tuberous sclerosis complex. Neuro Oncol 17: 15501559. [Crossref]

Copyright: (2020 Kirchner VA. This is an open-access article distributed under the terms of the Creative Commons Attribution License, which permits unrestricted use, distribution, and reproduction in any medium, provided the original author and source are credited. 